\title{
Reflection-based Whole-batch Discussion (RWD) as a Tool for Learning Proficiency Enhancement at Faculty of Medicine, Universiti Sultan Zainal Abidin in Malaysia: Toward Curriculum Development
}

\author{
Uday Younis $\mathrm{HA}^{\mathrm{a}}$, Haitham $\mathrm{MJ}^{\mathrm{c}}$, Marwan $\mathrm{SA}^{\mathrm{a}}$, Rana Abdulrahman $\mathrm{HAM}^{\mathrm{b}}$, Nor Iza $\mathrm{AR}^{\mathrm{a}}$, Nordin $\mathrm{S}^{\mathrm{a}}$ \\ ${ }^{a}$ Faculty of Medicine, Universiti Sultan Zainal Abidin (UniSZA), Health Campus, Terengganu, Malaysia \\ buniversiti Sains Malaysia, Health Campus, Department Of Medical Microbiology \& Parasitology, School Of Medical Sciences, Kelantan, Malaysia \\ ${ }^{\mathrm{c}}$ Rockingham Peel Group, Emergency Department, South Metropolitan Health Service, West Australia, Australia
}

\section{ABSTRACT}

INTRODUCTION: Different approaches have been endeavoured by medical educationists to produce highstandard graduates from medical school, including collaborative group discussions and reflective practice (RP) assignments. The current study aimed to evaluate the outcome of teacher-led whole batch discussion following RP tasks given to the students. The overall teaching approach is referred to as "Reflection-based whole-batch discussion (RWD)". MATERIALS AND METHODS: One hundred twenty-two medical students who attended the haematology course at the University Sultan Zainal Abidin were recruited into this study over 2 academic years. The first batch of students ( $\mathrm{n}=61$ ) was unexposed to the RWD intervention (RWD-unexposed) while the second batch from the following academic year ( $\mathrm{n}=61$ ) was exposed (RWD-exposed) to the intervention. Students adhered to the guidelines given by the instructor pertaining to the reflective practice (RP) before the sessions. A weekly RWD session was conducted where the instructor-led a dually interactive forum to discuss students' mistakes and misunderstandings as reflected within their write-ups. Exam results from both RWD-exposed and the RWDunexposed students were compared using the student t-test. RESULTS: The mean scores of students' results were significantly higher among RWD-exposed students compared to RWD-unexposed students in their essay questions and objective structured practical exam questions $(\mathrm{p}<0.01)$. However, RWD-exposed students scored significantly lower than the RWD-unexposed student's group in multiple true and false (MTF) questions. CONCLUSION: Implementing RWD is a promising teaching strategy in improving the academic achievement of medical students especially in answering essay questions. MTF questions format may be an incompetent tool for evaluating the impacts of new teaching strategies and therefore medical educationists recommended efficient alternative assessment tools such as OBA and EMQ for the sake of curriculum development in medical institutes.

KEYWORDS: reflection, whole-batch, discussion, Learning, curriculum development

\section{INTRODUCTION}

\section{Reflection and reflective practice (RP)}

These terms are interchangeable and used to describe the applications of reflection in the professional context.

Corresponding Author:

Dr. Uday Younis Hussein Abdullah Faculty of Medicine-Pathology Department University Sultan Zainal Abidin (UniSZA), Medical campus, Sultan Mahmud Street, 20400, Kuala Terengganu.

Tel No : +60103986315

E-mail : udayyounis@unisza.edu.my
Philosophies of reflection are minimally altered since it was introduced by the American educational philosopher John Dewey in 1933 who describe reflective thinking to clarify facts and identified future action to effectively approach an original problem. ${ }^{1} \mathrm{RP}$ is an effective competency-based learning model to learn from practice or learn by doing. ${ }^{2}$ Acquiring studying skills is essential for lifelong learning and thus, it is almost impossible for individuals to keep 
developing themselves without skills of reflection. The literature on RP continues to develop since Schön (1983) propagated the reflection concepts as reflectionin-action that involves on-the-spot thinking and reflection-on-action that involves thinking back on prior practice. Currently, RP is underused in the undergraduate curriculum through decades that have elapsed since it was first introduced. ${ }^{3}$ Among others, the most widely used reflective tool was Gibbs (1988) model of the reflective cycle. ${ }^{2}$

The reflection model developed by Gibbs is useful when an unanticipated event has happened, in case of experiencing something wrong or surprisingly well in the classroom. ${ }^{2}$ The proper setup of the RP sections is essential for obtaining the highest benefits for the students.

Student's beliefs, attitudes, and individual learning styles are important dimensions in the students' perceptions of RP. However, the significance of attitudes to RP for both learning and teaching in the literature is inadequately explored. ${ }^{4}$ Reflection as a reaction triggered by an experience is a multifaceted method of selfawareness in the term that each stage based on the results of the prior stage, consequently transforms the individual's learning. Nevertheless, reflective learning provides new understandings and future actions, which are desirable outcomes for the reflective practitioner.,5 Reid (1993) defines RP as an approach of reviewing a past practice in order to describe, analyse and evaluate learning from practice. ${ }^{7}$

$\mathrm{RP}$ is a means of developing self-awareness based on sets of skills dealing with real and difficult situations to create prospects for professional growth and development. The complexity of the RP meaning and applications contributed to the widely reported lack of clarity and understanding of this term. ${ }^{6}$ Consequently, the specific application in medical practice remains insufficient, and little known about the effectiveness or validity of RP as a teaching, learning, and assessment strategy. ${ }^{5}$ The goal of teachers in an ever-changing world is to become adaptive experts who continuously add to their knowledge and skills and who have the tendency to change from mechanistic practice to reflective practice. $^{7} \mathrm{RP}$ enables practitioners to use observations, articulations, and theorisation to transform practice. ${ }^{8}$ However, RP, though vague, has become an educational concept in health care institutes. ${ }^{9}$

\section{Whole batch discussion (WBD)}

Whole batch discussion (WBD), large group discussion (LGD), or Whole classroom discussion (WCD) are terms describing a form of classroom discourse whereby the task of information delivery is shared between the instructor and the students in such a way that a lecturer would supervise a class and present information for the students to learn but will also let the students take part by answering and discussing questions and answers. A large group is typically more than 50 students per group. ${ }^{10}$

\section{Reflection-based whole-batch discussion (RWD)}

RWD is an instructional, teacher-led, modified wholebatch discussion class preceded by and based on reflective practice. RWD is an innovative approach that promotes students to gain self-acquired knowledge, rather than merely receiving knowledge. Interactive lectures complemented by RWD would enhance deeper insight and longer-lasting retention of information as well as supporting autonomous learning. ${ }^{10}$ RWD is a conveniently modified form of classroom lecture whereby the task of information delivery is shared between the instructor and the students in such a way that an instructor would supervise a class composed of more than 50 students and present information for the students to learn but will also let the students take part by answering and discussing questions and their colleagues' answers. Independent individuals' deliberation among students is crucial in constructing sound knowledge and contributes to problems solving and triggering students' development of varieties of reasoning patterns. ${ }^{11}$ RWD is a fruitful teaching approach when used in conjunction with other teaching strategies. This can be attributed to the fact that RWD is characterised by being dually interactive, i.e. It is a platform to provide interaction between teacher and students on one hand, as well as enabling students to interact among themselves in groups on the other hand. Therefore, RWD helps students to share ideas using their own words evaluate and respond to their classmates' opinions, and encourages all including 
"quiet" students to become actively engaged in different topics discussions. Auditory learners especially benefit as RWD is more suitable for their learning style than the traditional visual (reading) style learners. Teachers can check on what students are retaining through brainstorming questions. In RWD, students are more open to ask questions and keep themselves focused on the subject under discussion since they might be called on to answer certain questions of relevance. ${ }^{12}$ Students in Europe, America, Australia, and Asia prefer applying collaborative activities in the classroom. ${ }^{10}$

Hence, the need to conduct a study attempting to evaluate the outcome of efforts taken to overcome the limitation in the write-up skills of the students as well as to preclude the misconceptions and the superficial learning of the students during the course demanded. ${ }^{13}$

This study aimed to define the role, benefit, and impact of RWD on academic achievement.

\section{MATERIALS AND METHODS}

Study design: It was an interventional study conducted in the pathology unit at the faculty of medicine in Universiti Sultan Zainal Abidin (UniSZA), Kuala Terengganu, Malaysia during the "haematology" course. A convenient sample of 122 medical students during their first year of the preclinical phase was included in the study. The enrolled students were those admitted during the academic years 2016-2017 (unexposed to RWD) and 2017-2018 (RWD adopted in the curriculum). Grades of participating students from the academic year 2017-2018 $(n=61)$ were compared to those of the previous 2016-2017 ( $n=65)$.

Bias was avoided by choosing two batches of students enrolled in two different academic years with nearly equal cumulative grade-point-average (c-GPA). The average pre-university grade-point-average (GPA) of the 2 study groups, RWD-exposed and unexposed was 3.91 \pm 0.09 and $3.91 \pm 0.06$ respectively, with $p=0.3$ and the c-GPA for all students was $3.91 \pm 0.08$. Moreover, efforts were taken to avoid any discrepancies or bias regarding the level of difficulty of the questions prepared for the two groups of students. The involved questions were selected from the nearly similar hot spots in the discussion topics contents and were vetted at department as well as the central vetting committees' levels.

\section{Instruction prior to RWD}

A preliminary session at the start of the course was set with students to highlight the guidelines for reflective learning and to optimise the participants reading and writing skills. Students adhered to the guidelines given by the instructor pertaining to the reflective practice (RP). Briefly, each student had to summarize a re-write of every lecture note delivered by the lecturer on the same day of lecture delivery to be submitted back to the instructor on the immediate next day. Thirty-five discussion topics delivered as six topics per week in hematology, immunology, transfusion, and molecular medicine were involved in the subsequent RWD sessions. A scheduled weekly-conducted WBD session was conducted where the instructor-led a dually interactive (teacher-student \& student-student) forum with the particular aim of discussing students' mistakes and misunderstandings as reflected within their writeups.

The instructor (first author) utilised a standard approach for the RWD session. The instructions were; knowledge should be correct, complete, and compressed in term of summarising or digesting lecture content not just rewriting lecture notes, focus on keyword and key concepts, focus on figures or diagram explaining the key concept, train to explain how by relating and reasoning, create mnemonics as an efficient tool for remembering and information recall, focus on the process, not the outcome, review periodically as three to six times over the course period and explain things to others and avoid misconception and misunderstanding as well as avoid superficial learning in term of incomplete or incorrect information. Students are encouraged to summarize the lecture note of each lecture in a one-paper.

All aspects of analysis mentioned in this research were compared with literature findings to see if the study is comparable or not and how this information can be used to guide lecturers to review their teaching strategies and to optimise the outcome of teaching in an outcomebased education strategy. 


\section{Mnemonics}

Implementing mnemonics is a transformational strategy aimed to simplify summaries and compress information by creating own to master new information, become independent and efficient learners who are capable of organising information in a memorable way that enhances information retention by converting difficult or unfamiliar information into more manageable information. ${ }^{14}$ Retention of facts and recall information (remembering) reducing stress and freeing up more cognitive resources for higher-order thinking as the information stored in long-term memory. Implementing mnemonics is a useful time-saving learning device to consolidate or recall information, helping students with intellectual disabilities remember important information, useful in medical school and during clinical work, link information to well-known knowledge, and appeal to humor or feelings. ${ }^{15}$

Acronym mnemonics (AM) is an abbreviation or word formed from the initial individual letters in a phrase or item list. Take the first letters in each item and form a word that relates to the main idea. AM is a letterassociation strategy that is the most popular and widely used mnemonic strategy to memorise a single word. ${ }^{16}$ Each letter of that word is associated with an important piece of information for remembering shortlists of items or steps. Keyword mnemonics based on connecting the new information with something already familiar and links a new word or concept to a known word that sounds similar. ${ }^{17}$ Combination mnemonics is applied by creating a map-like display and enhancing it with mnemonics to help learners recall the information. ${ }^{18}$

Assessment method: The instructor kept the anonymous approach for all misconceptions during RWD. Participants' level of comprehension was represented then by their marks obtained at the end of course (EOC) and end of semester (EOS) exams. Assessment tools were: short essay question (SEQ), problem-based question (PBQ), and objective structured practical examination (OSPE). A total of five SEQs and two PBQs were selected at the end of the course. All SEQs, PBQs, and OSPE, as well as multiple true-false (MTF) question included during the EOC, EOS and PRO-I examination. In each of the academic years 2016-2017 (Group-I) and 2017-2018 (Group-II) as depicted in Table 1, were constructed to have same difficulty levels.

Data analysis: Results expressed as mean \pm SD. Data were analysed using Statistical Package for Social Sciences (SPSS) version 18.0 for Windows. For each attribute, mean and standard deviation were calculated based on academic scores. The mean marks of the groups which took the exam (2016 vs 2017) were calculated and the significance derived via student t-test. A p-value of $\leq 0.05$ was considered statistically significant. Confidentiality of the data was strictly preserved.

\section{RESULTS}

Students marks for the essay (SEQ, PBQ), OSPE, and MTF questions at the end of course (EOC) assessment, respective end of semester (EOS) and professional-I (PRO-I) exams in the academic year 2016-2017 group-I (RWD-unexposed) was compared to those of the students in the academic group-II 2017-2018 (RWDexposed). RWD has significantly increased essay questions sore from $7.43 \pm 1.16$ to $8.07 \pm 1.02$ and OSPE question from $5.74 \pm 1.23$ to $7.62 \pm 1.15$.

\section{DISCUSSION}

Problems that students usually encounter during collaborative learning and the consequences of these problems have not yet been comprehensively explored. To promote effective learning and competent answering skills, collaborative learning comprising interactive whole -batch discussion and learning by assignments in the form of reflective practice was adopted in this study. The overall aim was to evaluate the extent to which RWD influences the academic performance of undergraduate preclinical medical students in UniSZA. The future expected benefit of the study for medical students is for them to become reflective practitioners and for local and national MBBS curriculum development. The research question was to find out whether RWD would significantly improve the overall academic performance of medical students with an evidence-based assessment method. The justifications of conducting this approach were the pre-observed weaknesses in the writing skills, suboptimal performance in EOC, EOS, and PRO-I 
Table I: Comparison of mean exam results scores between RWD-exposed and RWD-unexposed students in essay questions (SEQ and PBQ), OSPE, and MTF ( $\mathrm{n}=63$ )

\begin{tabular}{|c|c|c|c|c|c|}
\hline \multirow{2}{*}{ Variable } & \multicolumn{2}{|c|}{$\begin{array}{c}\text { Score } \\
\text { Mean (SD) }\end{array}$} & \multirow{2}{*}{$\begin{array}{c}\text { Mean Difference } \\
(95 \% \mathrm{CI})\end{array}$} & \multirow{2}{*}{$\begin{array}{l}t \text { statistic } \\
\text { (df) }\end{array}$} & \multirow{2}{*}{$p$-value* } \\
\hline & $\begin{array}{l}\text { RWD-unexposed } \\
\text { Students “2016" }\end{array}$ & $\begin{array}{l}\text { RWD-exposed } \\
\text { Students “2017” }\end{array}$ & & & \\
\hline $\begin{array}{c}\text { Essay } \\
\text { questions } \\
\text { (SEQ and } \\
\text { PBQ) }\end{array}$ & $\begin{array}{c}7.43 \\
(1.16)\end{array}$ & $\begin{array}{c}8.07 \\
(1.02)\end{array}$ & $\begin{array}{c}2.84 \\
(-1.02-0.25)\end{array}$ & $\begin{array}{l}-3.26 \\
(124)\end{array}$ & 0.001 \\
\hline OSPE & $\begin{array}{c}5.74 \\
(1.23)\end{array}$ & $\begin{array}{c}7.62 \\
(1.15)\end{array}$ & $\begin{array}{c}0.57 \\
(-2.30--1.46)\end{array}$ & $\begin{array}{l}-8.86 \\
(124)\end{array}$ & 0.001 \\
\hline MTF & 71.76 (9.53) & $\begin{array}{c}67.39 \\
(9.0)\end{array}$ & $\begin{array}{c}4.36 \\
(1.09-7.63)\end{array}$ & $\begin{array}{l}2.64 \\
(124)\end{array}$ & 0.009 \\
\hline \multicolumn{6}{|c|}{$\begin{array}{l}\text { *Independent } \boldsymbol{t} \text {-test } \\
\text { SEQ: short essay question. } \\
\text { PBQ: problem-based question. } \\
\text { OSPE: objective structured practical examination. } \\
\text { MTF: multiple true-false. }\end{array}$} \\
\hline
\end{tabular}

examination. Particularly in the SEQ part of the collaboration extensively. In group activities or examinations as well as procrastinating attitude in collaborative activities, learners can display a variety of studying the lecture notes. The significantly higher ways to describe, explain, relate ideas, develop different students' scores in answering essay questions (both SEQ kinds of reasoning patterns, draw conclusions, and find and PBQ) by the RWD-exposed student's group solutions to the presented problem under discussion. By indicates the advantageous outcome of adopting RWD implementing RWD higher cognitive level interactions in the medical curriculum. among them students can be achieved providing sustained and active engagement in learning. ${ }^{11}$

Although there was a statistically significant difference in student's MTF results between those RWD-exposed and RWD is an effective learner-centered approach that RWD-unexposed, however, the better performance was generally lasts 90-120 minutes with no interruptions. by the students who were RWD-unexposed. Researchers Tools implemented during the guided group reflection within the past decade have identified the MTF session included, reflective dialogical exercises and questions format as an inappropriate assessment tool of encourage the use of mnemonics written by the learners medical student performance. MTF questions format is to enable them to process, gain perspective on, and considered ineffective in discriminating student come to difficulties encountered on the road to competency, as many students tend to use guessing when becoming a professional; become independent and they answer such questions. Therefore, MTF might not efficient learners and, finally, to enable learners to be the optimum assessment tool to evaluate the power of become more self-aware. Educators can assign students a new teaching strategy such as the RWD approach. to write acronyms that enhance the recall of keywords Additionally, there are global difficulties in constructing and key concepts. Reflective learning incorporates the MTF questions to test the students' knowledge based on lessons of experience into one's body of knowledge and Bloom's taxonomy. ${ }^{19}$ For the aforementioned reasons, is committed to one professional and ethical values. ${ }^{19-22}$ many medical institutes and schools have decided to abandon the MTF question and substitute it with the one The conduction of RWD sessions was enhanced by a) best answer (OBA) or extended matching questions having clearly stated and visible information on the topic (EMQ) formats to overcome these intrinsic limitations and purpose of the discussion session on a PowerPoint of the MTF question format.19 slide, b) lettering on visual aids was more than 36 point font for PowerPoint to be read in the most distant part One of the authors (Abdullah $\mathrm{UYH})^{13}$ has been of the room test and it was tested in advance and see designing, enhancing, and monitoring productive how it looks from the back of the room, c) involving 
everyone in the room for active interaction and call on participants in different areas of the room, d) a brief summary of what happened during the past EOC and EOS examination, why it have happened that way, e) explaining what to do if the question differs from your expectations, f) using words as well as nonverbal behaviours to facilitate interaction, g) making sure pauses are long enough to allow participants to process the request, formulate a question or comment, and get attention. If no response, rewording and waiting again, h) asking the class to think about a question for 1-2 minutes and arranging their ideas about it before giving any responses. This gives students as a whole the chance to formulate their ideas (in a reflective learning style), and for the less confident participants to have more time to think, i) students explaining each other's notes creating situations where everyone can learn from others to generate productive interaction, connections and positive learning environment for everyone, $j$ ) using the audio-visual aids include PowerPoint presentations via projectors, interactive whiteboards, videos, simulations, and in-class audience response systems help to break up a monotonous and keep students' attention.11,12, k) RWD uncover whether lack of collaborative skills is the only or the most important antecedent to students' collaborative problems. Furthermore, RWD for learning proficiency development is consistent with the most updated advances offered by the Kern cycle model for medical curriculum development. ${ }^{23}$

A worth mentioning the advantage of having a teacherled RWD was to have the opportunity to monitor students' on-task behavior, managing group-work time, assigning individual roles, and establishing teamwork beliefs and behaviors, determining group norms, and facilitating activities. On the other hand, a noticeable limitation was likely to be related to cultural factors inherent to the Asian context, such as striving for group harmony and avoiding criticism, which might have influenced some of the results. ${ }^{10}$ High-order students in their learning groups were generally believed to be active, competent, or senior. Influential members tended to underestimate the intellectual capacity of low-status members, thus dominating the group while low-status students felt inferior and were not confident to talk and didn't feel safe to share. Friendship relations in groups were an obstacle to effective collaboration and inhibited them from constructing good arguments. Almost all students were able to effectively summarize the lecture note of each lecture in a one-paper.

\section{CONCLUSIONS}

Implementing RWD subsequent to reflective practice assignments given to medical students is a promising teaching strategy in improving the academic achievement of medical students especially in answering essay questions. It can also be concluded that adopting MTF as an assessment tool for comparing medical students' performances may result in misleading outcomes, especially when evaluating the impacts of new teaching strategies. Instead, it would be more appropriate to employ OBA and EMQ as efficient alternative assessment tools for the sake of curriculum development in medical institutes.

\section{RECOMMENDATIONS}

Further researches are recommended to develop a multicentered, validated RWD inventory keeping in view the basic structure of its strategy. Inculcating the RWD approach as a future curriculum component is recommended to reinforce the teaching methods beyond formal lecture. Combining interactive lectures with RWD slots to current practice appears to be promising in curriculum development. Our view of teaching by reflective learning is for the educators to balance the cognitive and collaborative aspects of RWD. Refinement of RWD concepts supports effective learning and teaching strategies in the undergraduate curriculum.

\section{ACKNOWLEDGMENT}

The authors would like to express sincere gratitude to the exam unit at the faculty of medicine for their assistance in data collection.

\section{CONFLICT OF INTEREST}

The authors state that they have no conflict of interest. 
1. Allen D \& Tanner K. Infusing Active Learning into the Large-enrollment Biology Class: Seven Strategies, from the Simple to Complex. Cell Biol Educ 2005; 4: 262-8.

2. Gibbs G. Learning in doing: A guide to teaching and learning methods. 1st ed. London: Oxford Centre for Staff and Learning Development, Oxford Polytechic, 1988.

3. Bruster BG \& Peterson BR. Using critical incidents in teaching to promote reflective practice, Refl Pract 2013; 14: 170-82.

4. Cole M. Learning through reflective practice: a professional approach to effective continuing professional development among healthcare professionals, Res Post-Comp Educ 2000; 5: 2338.

5. Elabbar AA. National Libyan Public Education Reform: Entire Transformative Strategies, 2020 2026. American J Educ Res 2017; 5: 1044-57.

6. Boyd EM \& Fales AW. Reflective learning: Key to learning from experience. J Human Psychol 1983; 23: 99-117.

7. Tashiro J, Shimpuku Y, Naruse K, Maftuhah, Matsutani M. Concept analysis of reflection in nursing professional development. Japan J Nurs Scie 2013; 10: 170-9

8. Helyer R. Learning through reflection: the critical role of reflection in work-based learning (WBL). J Work-Applied Manag. 2015; 7: 15-27.

9. Smith S, Martin JH. Practitioner capability: supporting critical reflection during workbased placement - a pilot study. Higher Educ Skills Work-Based Learn 2014; 4: 284-300.

10. Le H, Janssen J, Wubbels T. Collaborative learning practices: teacher and student perceived obstacles to effective student collaboration, Camb J Educ 2018; 48: 103-22.

11. Mustafa C \& Nurcan C. Students' talk during collaborative group discussion. The Eurasia Proc Educ Soc Scie 2014; 1: 307-10.

12. Sumera A. Large group teaching, an effective and efficient teaching methodology. J Asian Scie Res 2014; 4: 1-5.

13. Abdullah UYH, Jassim HM, Abdul Rahman NI, et al. Assessment of First-Year Students'
Metacognitive Ability in Faculty of Medicine, Universiti Sultan Zainal Abidin: Toward

Curriculum Development. Educ Med J 2017; 9: 17 -28 .

14. Amiryousefi M \& Ketabi S. Mnemonic instruction: A way to boost vocabulary learning and recall. J Lang Teach Res 2011; 2: 178-82.

15. Campos A, Camino E, Perez-Fabello MJ. Using the keyword mnemonics method among adult learners. Educ Geront 2011; 37: 327-35.

16. Hunt N. Using mnemonics in teaching statistics. Teach Stat 2010; 32: 73-5.

17. Qureshi A, Rizvi F, Syed A, Shahid A, Manzoor $H$. The method of loci as a mnemonic device to facilitate learning in endocrinology leads to improvement in student performance as measured by assessments. Advances in Physiology Education. 2014; 38: 140-4.

18. Wolgemuth JR, Cobb RB, Alwell M. The effects of mnemonic interventions on academic outcomes for youth with disabilities: A systematic review. Learn Disab Res Prac 2008; 23: 1-10.

19. Chandratilake M, Davis M, Ponnamperuma G. Assessment of medical knowledge: the pros and cons of using true/false multiple choice questions. Natl Med J India. 2011; 24: 225-8.

20. Cox E. Adult learners learning from experience: using a reflective practice model to support workbased learning. Reflec Prac 2005; 6: 459-72.

21. William T, Branch Jr, George M. Reflection-Based Learning for Professional Ethical Formation. AMA J Ethics 2017; 19: 349-56.

22. Banoobhai M. Critical reflection: tools for curriculum implementation and innovation. Soc Behav Scie 2012; 47: 175-9.

23. Wagner MJ, Fischer MR, Scaglione M, et al. GMS Journal for Medical Education 2017; 34:1-31. 